Соболева О. В.

\begin{abstract}
Аннотация. Цель исследования - выявить преимущества и недостатки использования Национального корпуса русского языка для решения задач, связанных с изучением звательных форм в современном русском языке. Новизна нашего исследования заключается в попытке оценить корректность результатов, полученных в ходе поисковых запросов по основному корпусу в составе Национального корпуса русского языка, выявлении сильных и слабых мест автоматизированного поиска звательных форм, обозначении неточностей, на которые исследователю необходимо обратить внимание, если он пользуется материалами Национального корпуса для изучения вокативов. В результате доказывается, что Национальный корпус русского языка дает богатый и разнообразный материал для всестороннего исследования звательных форм, однако интерпретация текстовых примеров и количественных данных, полученных в ходе автоматизированного поиска по корпусу, на современном этапе требует критического подхода и внимательного отношения к каждому из найденных случаев.
\end{abstract}

\title{
EN Vocative Forms in the Modern Russian Language (by the Material of the Russian National Corpus)
}

\author{
Soboleva O. V.
}

\begin{abstract}
The research aims to identify advantages and disadvantages of using the Russian National Corpus to solve issues related to the study of vocative forms in the modern Russian language. Novelty of the research lies in attempting to assess the correctness of the results obtained while making search queries on the main corpus as a part of the Russian National Corpus; identifying strengths and weaknesses of the automated search of vocative forms; specifying inaccuracies to which a researcher needs to pay attention if he or she uses materials from the National Corpus to study vocatives. As a result, it has been proved that the Russian National Corpus provides rich and diverse material for a comprehensive study of vocative forms, however, interpretation of textual examples and quantitative data obtained during an automated corpus search at the present stage requires a critical approach and careful attention to each of the examples found.
\end{abstract}

\section{Введение}

Национальный корпус русского языка (НКРЯ, 2022) дает современному лингвисту богатый материал для изучения самых разнообразных языковых явлений. Автоматизированный поиск по корпусу позволяет быстро собрать большое количество примеров из текстов, относящихся к заданному рамками исследования периоду. Особенности организации поисковых запросов на этом ресурсе делают возможным всестороннее изучение и такого сложного явления, как звательные формы в современном русском языке.

Актуальность нашей работы обусловлена необходимостью выявить достоинства и недостатки корпусных методов, применяемых в ходе лингвистических исследований. Национальный корпус русского языка, широко используемый сегодня для решения разнообразных научных задач, находится в стадии постоянного обновления: увеличивается количество доступных пользователю документов, совершенствуется механизм поиска. Автоматическая обработка большого объема текстов неизбежно приводит к отдельным неточностям, которые, конечно, постепенно исправляются создателями корпуса в ходе периодической переиндексации текстов НКРЯ, но все же могут исказить результаты отдельного поискового запроса. Именно поэтому пользователь, работающий с корпусом, должен знать о том, что следует учесть при интерпретации результатов, полученных в ходе поиска по НКРЯ.

Задачами нашего исследования являются уточнение места звательных форм в ряду грамматических явлений современного русского языка и рассмотрение возможностей, которые дает для исследования звательных (вокативных) форм Национальный корпус русского языка. 
Для решения поставленных задач в работе используются такие методы исследования, как общенаучные методы анализа и синтеза, лингвистический метод контекстологического анализа, социолингвистический метод анкетирования; при работе с языковыми примерами используются методы корпусной лингвистики.

Теоретическую базу исследования составляют лингвистические работы, предметом которых является категория падежа. Так, в частности, Р. О. Якобсон (1985) затрагивает вопросы, связанные с выделением падежа как особой грамматической категории и функциями падежей, Н. Ю. Шведова и другие авторы «Русской грамматики - 80» (1980) выделяют и описывают основные падежные формы современного русского языка. А. А. Зализняк (1973) рассматривает трудные случаи выделения падежей, Т. В. Булыгина и С. А. Крылов (1990), обращаясь к понятию падежа, говорят в том числе и о функции вокативных форм в современном русском языке, А. В. Полонский (2001), сопоставляя русский и польский языки, поднимает вопрос о грамматическом статусе звательного падежа в современном русском языке, Г. И. Кустова и другие авторы «Русской корпусной грамматики» включают звательную форму (вокатив) в число так называемых «малых падежей» (Материалы к Корпусной грамматике..., 2018), М. А. Даниэль (2009) рассматривает историю новых звательных форм на материале письменных текстов, привлекая при этом данные НКРЯ.

Практическая значимость исследования заключается в возможности применения его результатов в практике преподавания современного русского языка. Отдельные текстовые примеры и приемы работы с поиском звательных форм в НКРЯ могут быть использованы для составления учебных заданий по курсу «Информационные технологии в лингвистике».

\section{Основная часть}

Вопрос о месте звательных форм в грамматической системе современного русского языка до сих пор остается дискуссионным. С одной стороны, совершенно очевидно, что звательная падежная форма, характерная для древнерусского языка, была утрачена уже к XIV-XV вв. (Иванов, 1990, с. 275) и на современном этапе функционирования русского языка звательный падеж не может рассматриваться в рамках шестикомпонентной падежной парадигмы (Русская грамматика, 1980, с. 474). С другой стороны, отдельные сохранившиеся до наших дней примеры исторических звательных форм и так называемые новые звательные формы, появившиеся предположительно в начале XIX века и зафиксированные в письменных текстах уже начиная с середины XIX века (Даниэль, 2009, с. 234), сегодня могут считаться полноправными фактами речи.

Как показало проведенное нами анкетирование студентов старших курсов гуманитарного факультета Пермского национального исследовательского политехнического университета, все опрошенные отмечают, что сами регулярно используют звательные формы и встречают их в речи своих знакомых. В качестве примера приведем один из ответов: «Я довольно часто употребляю такие формы в повседневной жизни. Постоянно употребляю обращения: мам, бабуль. Обращаюсь к друзьям или знакомым: Леш, Сереж».

Широкое распространение в сочетании с непроясненным грамматическим статусом делает звательные формы притягательным объектом обсуждения в научно-популярном дискурсе (Зенков, 2009).

Как нам представляется, примером современного взгляда на проблему грамматического статуса звательных форм может являться исследовательская позиция авторов «Русской корпусной грамматики», которые не выделяют звательный падеж в качестве самостоятельного падежа и рассматривают звательные формы в ряду «форм со спорным статусом, близких к падежу» (Кустова, 2011). Такой подход позволяет обозначить звательные формы как особое грамматическое явление, не расширяя при этом рамки традиционной шестипадежной системы.

Богатые возможности для изучения звательных форм во всем их многообразии открывает перед исследователями Национальный корпус русского языка.

Какие же преимущества дает корпус исследователю вокативов? Безусловно, это объем текстов, по которым ведется поиск. Так, в декабре 2021 года поиск звательных форм по основному корпусу в составе НКРя позволяет нам выбрать необходимые примеры из 126901 документа (количество слов - 337025 184).

Количество найденных примеров позволяет увидеть, насколько активны в современной речи исторические звательные формы, и опровергнуть мнение о том, что следов древнерусской звательной формы в современной речи не сохранилось (Иванов, 1990, с. 273). Корпусные данные свидетельствуют о том, что исторические звательные формы используются и в функции обращения, и как междометия. Функция обращения реализуется, как правило, только в условиях особой стилистической возвышенной окрашенности текста (здесь и далее примеры взяты из Национального корпуса русского языка: ruscorpora.ru; выд. наше. - O. C.):

«Русь Твоей Милостью, Господи, рождает дивную красоту» [В. Г. Распутин. Новая профессия (1998)];

«Единственные слова, обращенные Им к Отцу о мучителях, были: Отче, прости им: они не знают, что творят!» [митрополит Антоний (Блум). Страстная седмица (1980)];

«В частности, после произведенной замены поминовения царя в одной из молитв утреннего богослужения по всем церквам России должны были произноситься такие слова: “Всепетая Богородице... спаси благоверное Временное правительство наше, ему же повелела еси правити” [Михаил Бабкин. «Священство» против «царства»? // «Родина», 2007].

Однако в корпусе можно найти и примеры того, что исторические звательные формы в функции обращения могут употребляться в стилистически нейтральном разговорном или подчеркнуто сниженном контексте:

«Давай-ка выпьем ерша с тобой, друже» [В. Я. Шишков. Угрюм-река. Ч. 1-4 (1928-1933)]; 
«Герман, друже! Мне крайне необходимо увидеться с тобой сегодня вечером» [Дмитрий Емец. Таня Гроттер и колодец Посейдона (2004)];

«Заткнись, отче, - отвечала Тонечка» [Егор Радов. Змеесос (2003)].

В значительном числе примеров, которые предлагает Национальный корпус, исторические звательные формы используются как междометия:

«О господи, - вздохнула Марина, - ну, пойдем в вокзал» [Виктор Астафьев. Пролетный гусь (2000)];

«Боже, что с ней сделалось!» [Алексей Варламов. Купавна // «Новый Мир», 2000].

Найденные в корпусе примеры в достаточной степени иллюстрируют положение о том, что исторические звательные формы могут использоваться как средство стилизации (Иванов, 1990, с. 273):

«Когда отправляешься, друже? - посуровел князь» [Андрей Белянин. Свирепый ландграф (1999)];

«И речет: прибыл, владыко, по зову твоему» [Роман Волков, Сергей Чугунов. Былина о богатыре Спиридоне Илиевиче (2002)].

Корпус позволяет проследить и особую функцию исторических звательных форм - употребление их в качестве этикетных формул обращения в церковной среде:

«Отче, расскажи странникам! - обратился митрополит, как бы подтрунивая» [Сергей Шаргунов. Чародей (2008)]; «Благослови, отче... - Отец Макарий упал старцу в ноги» [Николай Кокухин. Невидимые старцы, или Афон сокровенный // «Наука и религия», 2010];

«Отче, не знаю, как вести себя с братией в нашей общей келье и за трапезой» [Майя Кучерская. Современный патерик: чтение для впавших в уныние (2004)];

«Да, владыко, - я отвечала легко и почтительно, не отводя глаз» [Елена Чижова. Лавра // «Звезда», 2002];

«Епископ Анатолий: Как благословите, Владыко, я делаю с Вашего благословения, здесь не может быть отказа» [митрополит Антоний (Блум). Дом Божий. Три беседы о Церкви (1990-1991)].

Большим количеством разнообразных примеров представлены в Национальном корпусе и новые звательные формы. Анализ результатов поиска позволяет согласиться с мыслью М. А. Даниэля (2009) о том, что новая звательная форма характерна терминов родства, «причем в первую очередь для тех из них, в которых в форме именительного падежа единственного числа ударение падает на предпоследний слог» (с. 225). Рассмотрим некоторые из найденных примеров, подтверждающих эту закономерность:

«Мамуль, секундочку, я только этот тайм доиграю...» [Елена Павлова. Вместе мы эту пропасть одолеем! // «Даша», 2004];

«Мам! - начал он, макая сырник в сметану и блестя глазами» [Вера Белоусова. Второй выстрел (2000)];

«Спасибо, мамусь, - сказала Полина, поднявшись из-за стола» [Руслан Киреев. Мать и дочь (1964)];

«Пап, правда? - не совсем еще верила Таня» [Людмила Улицкая. Казус Кукоцкого [Путешествие в седьмую сторону света] // «Новый Мир», 2000];

«Запомнил, папуль? - сказала дочка. - Бульвар Профсоюзов» [Виктор Конецкий. Вчерашние заботы (1979)];

«Папк! Папк! Вон он!» [М. М. Рощин. Старый Новый год (1967)];

«Бабуль, что с тобой? - спросил он» [Дмитрий Калмыков. Зов глубин // «Волга», 2015];

«Бабусь, че там, козье-то можно?» [Нонна Мордюкова. Казачка (2005)].

Новые звательные формы активно образуются от имен собственных, что тоже подтверждается данными корпуса:

«Привет, Алеш, - говорит, как всегда, щурясь» [А. А. Шепелев. Поход и гости «каннибалов» (2004) // «Волга», 2012];

«Правда, Коль?» [Юрий Трифонов. Дом на набережной (1976)];

«А что ты, Жень, говоришь, сделал?» [Г. М. Артемьева. Фата на дереве (2012)];

«Андрюх, - подал голос Петр Сергеевич, - ну чего ты мурыжишься?» [Виктор Пелевин. Желтая стрела (1993)]; «Вы что такие? Зой! А Володя где?» [М. М. Рощин. Спешите делать добро (1979)];

«Лен, а Лен, а винные куда? - спросил он, оборачиваясь на заднюю дверь ларька, где сейчас сидела продавщица» [Фазиль Искандер. Бедный демагог (1969)];

«Серег, а Серег!.. - Да, Михалыч, - кивнул я. - Нам бы так, да» [Андрей Волос. Недвижимость (2000) // «Новый Мир», 2001];

«Катюш, отправь, пожалуйста, на всякий случай, еще раз» [Кошки форева! (2008)].

Термин родства в звательной форме может сочетаться с именем собственным. Эта характерная для современной речи ситуация отражена в корпусе:

«Спасибо, теть Маш, я побегу. У меня там колбаса. Он, наверное, из-за колбасы пришел, - заторопился Женька» [Г. М. Артемьева. Фата на дереве (2012)];

«До завтра, теть Ляль» [Екатерина Завершнева. Высотка (2012)];

«Теть Кать, а давай я с тобой, а?» [Марина Зосимкина. Ты проснешься. Книга первая (2015)];

«Дядь Федь, а еще кого не надо?» [Борис Можаев. Живой (1964-1965)].

Поиск по корпусу позволяет найти примеры использования звательных форм не в роли обращения, а в роли подлежащего, то есть в функции именительного падежа. Это явление, наблюдавшееся уже в текстах XVIII века, свойственно и современной речи:

«Быть может, суждено ей прославить род человеческий, и потому дарит ей владыко-солнце авансом благосклонный взгляд?!» [Екатерина Маркова. Тайная вечеря (1990-2000)];

«...и однажды отче сказал мне...» [Ю. О. Домбровский. Факультет ненужных вещей. Ч. 3 (1978)]; 
«Уж после, когда накормила мальчонку, как бы готовно усыновила его, положив в зыбку рядом со своим, тогда и выяснилось со слов брата, откуда крохотный человече взялся тут» [Владимир Личутин. Вдова Нюра (1973)].

Как показывают найденные примеры, это явление широко распространено при сочетании термина родства (который используется в звательной форме) с именем собственным:

«Дядь Саша направился к двери» [Виктор Ремизов. Воля вольная // «Новый мир», 2013];

«Теть Тома собрала деньги, которые на Димку выплатили, отдала Насте» [Марина Ахмедова. Сталинград. Возвращение // «Русский репортер», 2014].

В ряде примеров, найденных в корпусе, можно обнаружить различные средства письменной передачи интонаций устной речи, которые свойственны для вокативов:

«Люба поворошила мои волосы, теребнула за ухом: - Сере-ож!» [Виктор Астафьев. Обертон (1995-1996)];

«Молодая женщина в свою очередь слышит (и тоже понимает) доносящееся со двора истеричное мяуканье и вслед вскрик оцарапанного малыша: Маа-ам!» [Владимир Маканин. Кавказский пленный (1995)].

Таким образом, мы отмечаем, что Национальный корпус дает возможность во всей полноте увидеть особенности употребления звательных форм в современной речи. При этом нельзя утверждать, что исследователь вокативов может во всем положиться на результаты автоматизированного поиска по корпусу. Создатели НКРЯ предупреждают пользователей о том, что полноценный поиск звательных форм возможен только по корпусу со снятой омонимией. И это действительно так: при анализе результатов поиска звательных форм по всему объему основного корпуса выяснилось, что в выдаче встречаются примеры, не имеющие отношения к вокативам. В эту категорию попадают слова с дефисным написанием (сложные слова либо сегментированные для передачи интонации устной речи):

«ПАП-мазок это тест, который определяет наличие дисплазии» [Ирина Плыткевич. Разбираемся с прививками. Часть 8. Папиллома (2017.08.27)];

«Для радикального уменьшения габаритов, оружие перекомпоновано по схеме булл-пап, то есть затворная коробка играет роль приклада» [Юрий Бондарь. ФГ-42 - винтовка немецкого парашютиста // «Криминальный отдел», 2012];

«Род деятельности: авантюрист, лже-сын Василия Иоанновича Шуйского, поэт» [Мария Нестеренко. С ними не соскучишься. Выжигин, Калиостро и другие трикстеры русской литературы (2017.04.07)];

«Музыкальный стендап-комик с Украины, прославившийся за счет юмористических песен на грани фола» [Музыка // «Русский репортер», 2014];

«Как Ленин и большевики, - прокартавил Черныш, - все по тюр-рь-мам да по тюр-рь-мам...» [М. Е. Окунь. Тетерев (2014) // «Волга», 2015].

К звательным формам поисковая система НКРЯ может ошибочно отнести некоторые имена собственные:

«Зато правда [Кхалиси Венсди], а Вы из какого города?» [коллективный. Суши Мин - ТЦ Республика... когда особо нет выбора... (2014.12.03)];

«А знаменитый израильский архитектор Моше Сафди» [Владимир Бейдер. Избрали прецедентом // «Огонек», 2014];

«Но в экономике, как ожидается, Моди будет прагматиком» [Евгений Пахомов. Поговорить есть с кем // «Огонек», 2014].

Сложность для автоматического распознавания представляют собой и отдельные аббревиатуры, ошибочно причисленные к вокативам:

«9 мая вступили в силу изменения в КоАП, касающиеся уклонения от исполнения административного наказания» [Мария Клапатнюк. Рабочие сутки (2013.05.14) // «Новгородские ведомости», 2013];

«Заведующая Луньшинским ФАП занесена в Книгу Почета области» [Юрий Никулин. Сельские дороги Елены Мироновой (2013.04.12) // «Новгородские ведомости», 2013].

Наличие нерелевантных примеров в результатах поиска по корпусу с неснятой омонимией создает серьезные сложности для количественной интерпретации найденных примеров. В этом случае исследователь звательных форм не может воспользоваться статистическими инструментами, предлагаемыми НКРЯ, то есть обратиться к функциям распределения по годам, статистики и n-граммов. Все эти инструменты корпуса покажут корректные результаты только при использовании на материале подкорпуса со снятой омонимией, а это значительно снижает объем найденных примеров. Так, по состоянию на декабрь 2021 года поиск звательных форм по подкорпусу со снятой омонимией предлагает исследователю всего 156 документов, содержащих 669 вхождений. Такой объем примеров существенно ограничивает исследовательские возможности и сопоставим с результатами поиска, осуществляемого методом сплошной выборки вручную (для сравнения: поиск звательных форм по всему объему основного корпуса дает нам 10137 документов, в которых содержится 63649 вхождений).

\section{Заключение}

Подводя итог, можно сделать следующие выводы: характерные для современной речи звательные формы представляют собой сложное грамматическое явление со спорным статусом, близкое к падежу. При анализе примеров из текстов XX-XXI вв. мы можем обнаружить в них соседство отдельных сохранившихся исторических вокативов с так называемыми новыми звательными формами, представленными в первую очередь именами собственными и терминами родства. 
Использование автоматизированного поиска по НКРЯ для изучения вокативов в современном русском языке имеет свои сильные и слабые стороны. К преимуществам мы можем отнести обилие примеров звательных форм, которые позволят исследователю увидеть изучаемое явление во всем его многообразии, если поиск задан по всему объему основного корпуса.

К числу недостатков стоит отнести ошибки выдачи при поиске звательных форм по всему объему основного корпуса, который включает в себя и тексты с неснятой омонимией, затрудняющей автоматическое распознавание вокативов. Объем же подкорпуса со снятой омонимией невелик и - как следствие - количество примеров звательных форм, найденных при работе с эти подкорпусом, не очень представительно. Кроме того, на современном этапе невозможно использовать статистические инструменты НКРЯ при обработке всех найденных в основном корпусе примеров звательных форм, так как среди них могут оказаться нерелевантные. Статистическими инструментами можно полноценно пользоваться только на материале примеров звательных форм, найденных в подкорпусе со снятой омонимией. Остается надеяться, что объем этого подкорпуса со временем будет увеличиваться, что в будущем даст исследователям вокативов возможность получить более представительные в количественном отношении результаты поиска.

Перспективы дальнейшего исследования видятся нам в изучении возможностей, которые дают для описания звательных форм современного русского языка отдельные подкорпусы НКРЯ - мультимедийный и параллельный.

\section{Источники | References}

1. Булыгина Т. В., Крылов С. А. Падеж // Лингвистический энциклопедический словарь / гл. ред. В. Н. Ярцева. М.: Советская энциклопедия, 1990.

2. Даниэль М. А. «Новый» русский вокатив: история формы усеченного обращения сквозь призму корпуса письменных текстов // Корпусные исследования по русской грамматике / ред.-сост. К. Л. Киселева, В. А. Плунгян, Е. В. Рахилина, С. Г. Татевосов. М.: Пробел, 2009.

3. Зализняк А. А. О понимании термина «падеж» в лингвистических описаниях // Проблемы грамматического моделирования / под ред. А. А. Зализняка. М.: Наука, 1973.

4. Зенков С. Новая звательная форма. 2009. URL: http://gramota.ru/forum/veche/118213/\#mess118213

5. Иванов В. В. Историческая грамматика русского языка: уч. для студ. пед. ин-тов по специальности «Русский язык и литература». М.: Просвещение, 1990.

6. Кустова Г. И. Падеж. 2011. URL: http://rusgram.ru/Падеж

7. Материалы к Корпусной грамматике русского языка. СПб.: Нестор-История, 2018. Вып. 3. Части речи и лексико-грамматические классы / отв. ред. В. А. Плунгян, Н. М. Стойнова.

8. Национальный корпус русского языка (НКРЯ). 2022. URL: https://ruscorpora.ru

9. Полонский А. В. Эготив, вокатив, номинатив: субъект и падежная парадигма // Русский язык за рубежом. 2001. № 3. URL: http://gramota.ru/biblio/magazines/ryzr/rzr2001-03/28_197

10. Русская грамматика: в 2-х т. / гл. ред. Н. Ю. Шведова. М.: Наука, 1980. Т. 1. Фонетика. Фонология. Ударение. Интонация. Словообразование. Морфология.

11. Якобсон Р. О. К общему учению о падеже // Якобсон Р. О. Избранные работы. М.: Прогресс, 1985.

\section{Информация об авторах | Author information}

RU Соболева Ольга Владимировна ${ }^{1}$, к. филол. н.

${ }^{1}$ Пермский национальный исследовательский политехнический университет

EN Soboleva Olga Vladimirovna ${ }^{1}, \mathrm{PhD}$

${ }^{1}$ Perm National Research Polytechnic University

${ }^{1}$ olga.v.soboleva@gmail.com

\section{Информация о статье | About this article}

Дата поступления рукописи (received): 28.12.2021; опубликовано (published): 28.02.2022.

Ключевые слова (keywords): современный русский язык; падеж; звательная форма; Национальный корпус русского языка; корпусная лингвистика; modern Russian language; case; vocative form; Russian National Corpus; corpus linguistics. 